\title{
Influence of the composition and agglomeration pressure on the compaction level of the fertilizers based on biomass ash and digestate
}

\author{
Marek Wróbel", Jarosław Frączek, Krzysztof Mudryk, Marcin Jewiarz and Krzysztof Dziedzic \\ University of Agriculture in Krakow, Faculty of Production and Power Engineering 120 Balicka street, 30-149 Krakow, Poland
}

\begin{abstract}
The paper presents the results of research aimed at determining the influence of the composition of the fertilizer mixtures and the compaction pressure on the specific density and density index of fertilizer granules. Investigated mixtures were prepared from fly ash from power plant fuelled by biomass and digestate from biogas plant. The urea, sulfur and phosphorite were also added as enhancing additives. For granule samples made on a strength machine, their specific density was determined on a quasifluidpycnometer. To determine the effect of agglomerate pressure on the compaction process, the absolute density of the materials was omitted. In such case it was needed to introduce a density index $A_{I}$. Such a presentation of the results obtained has made it possible to clearly determine how the density of the test mixture results in the applied agglomeration pressure. The specific density of the resulting granules was in the range of $0.85-1.27 \mathrm{~g} / \mathrm{cm}^{3}$. The determined density index for the given pressure was in the following ranges: $0.44-0.49 \mathrm{~g} / \mathrm{cm}^{3}$ (pressure 100MPa), $0.47-0.51 \mathrm{~g} / \mathrm{cm}^{3}$ (pressure $\left.150 \mathrm{MPa}\right) 0.51-0.59 \mathrm{~g} / \mathrm{cm}^{3}(200 \mathrm{MPa}$ pressure). This means that, regardless of the contribution of components to the mixture at the given pressure, a similar degree of compaction was obtained.
\end{abstract}

\section{Introduction}

In the anaerobic digestion process which takes place in biogas plants, the biogas and digestate ist obtained which is residue with high fertilizer potential. During this process of the substrate reduction of the organic matter content, decomposition of the compounds, fragmentation of the solid substrate fractions and partial hygienisation, and most importantly cause relatively small losses of the fertilizers occurs $[1,2]$.

Decomposition deegree usually ranges from 30 to $60 \%$ of organic matter. During anaerobic digestion, $80 \%$ of the biodegradable substance is converted into biogas [3]. Digestate contains: biomass of fermenting microorganisms, non-fermented organic compounds and minerals. Because of the nitrogen, phosphorous and potassium content in the mineral form directly accessible to cultivated plants, these substances are very valuable from the fertilizer point of view. In addition, the digestate as organic matter in the soil is mineralized and it is a source of nutrients and positively affects the physicochemical properties of soils. The digestate residue contains nitrogen both in organic and inorganic form [4, 5]. In slurry based digestate mixed with different types biomass, nutrient content falls within the following ranges: general nitrogen - 3.4-4.0; $\mathrm{N}^{-\mathrm{NH}_{4}}$ 2.4-2.9; $\mathrm{P}$ - 0.8-1.2; $\mathrm{K}-2.7-3.1$ - values are given $\mathrm{g} / \mathrm{l}[6]$. The increase in the number of biogas plants on the territory of Poland results in higher amount of digestate to be utilise. The amount of fermentation residue produced by a single biogas plant is difficult to manage locally. According to the European Nitrates Directive [7], the annual nitrogen limit is $170 \mathrm{~kg}$ per hectare. On the other hand, research conducted by Dohler and Schliebner [8] shows that it is economically feasible to transport untreated residue up to $10 \mathrm{~km}$ from the site.

Therefore, another economically reasonable way of using the fermentation residue for fertilizers need to be found. One of them is the production of organic granulated fertilizers from fermented or organic-mineral fertilizers based on fermentation residues and other mineral substances supplementing nutrients missing from the fermentation. As an additive in such granules may be fly ash from a professional power plant fuelled by biomass. Studies have shown that ash from biomass combustion may find use as a mineral fertilizer [9] or as an ingredient in compound fertilizers with organic substances $[10,11]$. These main materials may be supplemented by other components of the fertilizer mixture such as sulfur, urea, phosphate; depending on the required fertilizer composition.

Taking into account the variety of morphological, granulometric and physical properties of these raw materials, the only promising granulation method is pellet production. This form of fertilizer, in the form of stable dimensions and density granules, reduces transportation costs and enables uniform dosing of fertilizer on the field. Irrespective of the ingredients'

*Corresponding author: marek.wrobel@urk.edu.pl 
contribution to the mix, the granulation process should allow production a uniform granule. The results of experimental and analytical studies which are designed to investigate the particle trajectory on and off the spreader, the uniformity of the fertilizer distribution depends mainly on the physical properties of the fertilizer. The most often parameters are: particle size, friction coefficient, aerodynamic drag, mechanical strength and density. The specific density of the granules depends not only on the specific density of the raw materials but also on the pressure of the agglomeration. A comprehensive experimental and analytical study performed to investigate particle trajectories on and off a centrifugal spreader. The performance of fertilizer distributors and hence the evenness of the spread pattern depends to a large extent on the physical properties of the fertilizer.

Five important properties which affect particle motion are reviewed, namely particle size and particle size distribution, coefficient of friction, coefficient of restitution, aerodynamic resistance, and particle strength. As the biomass studies show [12-14], the properties of the raw material, apart from the process parameters, significantly influence the characteristics of the obtained granules. the degree of fragmentation of the raw material has a significant effect on the density of biomass granulates [15]. What is also important, the significant share of dusty fractions in the raw material increases the stability of granules [16, 17]. In the case of fertilizer mixtures based on ash and digestate, the physical parameters of the substrates and their composition have a decisive importance of the granulate characteristics [18, 19, 20, 21].

Therefore, the optimum quality of the raw material, process parameters and the relationships between them need to be establish, so the produced granulate meets the quality requirements.. That is why it is so crucial to know the basics of the agglomeration process of the mineral-digestate mixtures.

According to this information, the main objective of the study was to determine the effect of the composition parameters of the fertilizer mixtures and the agglomeration pressure on the specific density and the degree of compaction of the resulting granules.

\section{Material and methodology of research}

The research was carried out on fertilizer mixtures which composition was developed by prof. Witold Grzebisz from the University of Life Sciences in Poznan (Member of the Research Consortium). The raw materials for the mixtures production were fly ash from the Połaniec power plant fuelled by biomass and a digestate form Piekoszów biogas plant. Additional components of valorising were sulfur, urea and phosphorite. The bulk composition of the fertilizer mixtures according to which the granules samples were prepared is shown in Table 1. The share of the main constituents (fly ash and digestate) varies from 25 to $70 \%$, each blend contains $5 \%$ urea addition. In addition, some blends contain $5 \%$ sulfur or $15 \%$ phosphate addition.
Table 1. Composition (mass based) of investigated fertilizer mixtures.

\begin{tabular}{|c|c|c|c|c|c|c|c|}
\hline Component & B1 & B2 & B3 & B4 & B5 & B6 & B7 \\
\hline Ash & 70 & 65 & 50 & 50 & 45 & 30 & 25 \\
\hline Postferment & 25 & 25 & 25 & 45 & 45 & 45 & 70 \\
\hline Urea & 5 & 5 & 5 & 5 & 5 & 5 & 5 \\
\hline Sulfur & 0 & 5 & 5 & 0 & 5 & 5 & 0 \\
\hline Phosphorite & 0 & 0 & 15 & 0 & 0 & 15 & 0 \\
\hline
\end{tabular}

In order to minimize the influence of the particle size of the materials included the fertilizer mixtures (especially the digestate which may contain particles larger than 5 $\mathrm{mm}$ ), all the components of the mixture are uniformly dimensioned by grinding on the IKA A11 BASIC laboratory mill to a grain size of less than $1 \mathrm{~mm}$. From such prepared components, specified mixtures were prepared, with moisture content $15 \%$. The moisture level of the mixture was determined on the basis of preliminary studies. Three levels of humidity were tested, 12, 15 and 18\%. A sample of $50 \%$ ash content and digestate at $200 \mathrm{MPa}$ and humidity of $15 \%$ was characterized by the highest density. Depending on the needs, water was added to the mixes to allow for the desired moisture level of the samples. Each of the test mixture variant was prepared in amount about $200 \mathrm{~g}$. The weighed ingredients (fertilizers and water) were mixed in a laboratory mixer to produce homogeneous mixtures with a set humidity. The process of agglomeration of fertilizer mixtures was carried out on the EDZ20 type strength machine. Agglomeration pressure levels were set at 100, 150 and $200 \mathrm{MPa}$. The sample compaction process was carried out in special agglomeration set to produce $8 \mathrm{~mm}$ diameter granules (Figure 1).

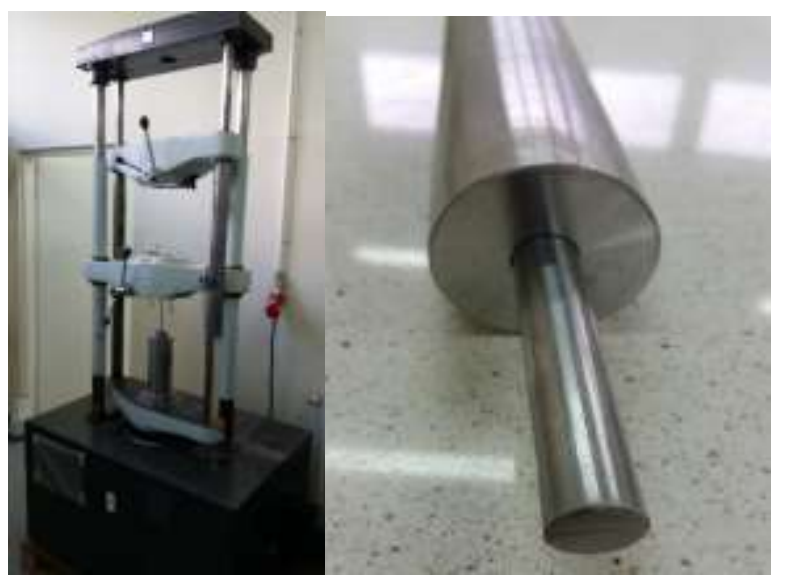

Fig. 1. Agglomeration stand.

The moisture content of component and mixtures $\left(\mathrm{M}_{\mathrm{ad}}\right)$ in as analysed state (air dry) was determined according 
to the PN-EN ISO 18134-3:2015-11 [19] standard. In this analysis laboratory dryer (SLN 160, POLEKO from Wodzisław Śląski, Poland) was used. The procedure rely on drying of small amount of the material $(1 \pm 0,05 \mathrm{~g})$ in air at $105^{\circ} \mathrm{C}$. The moisture content was determined according to difference in sample weight before and after drying [19]. AS 160.R2 analytical balance was used with readability $0,1 \mathrm{mg}$ produced by Radwag, Radom, Poland The absolute density of raw materials (material density without inner pores) was carried out on a AccuPyc 1340 gas pycnometer from Micromeritics, USA. Device measured the volume of the sample by measuring the change in helium pressure within the calibrated chamber volumes. The device uses the direct dependence of Clapeyron on the assumption that the temperature within one measurement does not change (1 and 2).

$$
\begin{gathered}
V=\frac{V_{c e l}-V_{e x p}}{\frac{p_{1}}{p_{2}}-1} \\
\rho_{r z}=\frac{m}{V}
\end{gathered}
$$

where: $\quad V$ - volume of the sample

$V_{c e l}$ - volume of the sample chamber

$V_{\text {exp }}$ - volume of the control chamber

$p_{1}-$ pressure before decompression

$p_{2}-$ pressure after decompression

$m$ - mass of the sample

$\rho_{r z}-$ absolute density

The specific density measurements of granule were performed with use of The GeoPyc 1360 (Micromeritics Instrument Corp.) based on displacement methods. The sample is placed vessel (inner diameter $50 \mathrm{~mm}$ ) filled with Dry Flo, which is a powder composed of small, rigid spheres with high ability to move (quasi-fluid). The material inside test vessel is agitated and gently compressed (consolidation force is $140 \mathrm{~N}$ ) and all this parameters are controlled by computer. Before measurement apparatus measures the volume of Dry Flo substance in the same way. After measurement is done, based on the diameter of the vessel, displacement (with and without sample), and mass of the sample, density were calculated, by implemented algorithm.

To determine the effect of agglomerate pressure on the compaction process, the absolute density of the materials was omitted. This could be achieved by introducing a density index $A_{I}$ of material into the analysis. This indicator tells how much of the resulting density of a granule is approaching the common density of the constituents of the granules. Such a presentation of the results make it possible to clearly determine the density of the test mixture resulting in the applied agglomeration pressure. This indicator, bypassing the absolute density factor of the components of the blend, allows comparison of the results obtained for the test mixtures and determine which of them is characterized by high vulnerability for agglomeration Density index can be calculated according to the equation (3):

$$
A_{I}=\rho / \rho_{r z}
$$

where: $\quad \rho$-specific density of the granules $\rho_{r z}-$ absolute density

Based on the absolute density of raw materials and specific density of granulates, porosity $p_{Z}$ of granulates was determined.

\section{Research results}

The results obtained for specific density were ranged from $0.85 \mathrm{~g} / \mathrm{cm}^{3}$ (B7 $\left.150 \mathrm{MPa}\right)$ to $1.27 \mathrm{~g} / \mathrm{cm}^{3}$ (B3 $200 \mathrm{MPa}$ ) (Figure 2). For a given pressure the specific density value is in the range of $0.92-1.05 \mathrm{~g} / \mathrm{cm}^{3}$ (pressure $100 \mathrm{MPa}$ ), $0.85-1.1 \mathrm{~g} / \mathrm{cm}^{3}$ (pressure 150MPa) $0.93-1.27$ $\mathrm{g} / \mathrm{cm}^{3}$ (200MPa pressure). For samples B6 and B7 at $100 \mathrm{MPa}$, the specific density of the granules were determined to be higher than at $150 \mathrm{MPa}$. This difference was respectively 0.05 and $0.09 \mathrm{~g} / \mathrm{cm}^{3}$. In other cases, the specific density of the granules increases as the compaction pressure increases. Comparison of the specific density of the obtained granules between the test mixtures is not conclusive. By analysing the obtained results, we can distinguish a group of granules (B1-B3) which specific density is higher in selected pressure groups compared to the others. However, the question arises as to how much is the effect of the applied pressure and how much influence of the density of ingredients constituting the blend? Therefore, the degree of compaction of the obtained granulates was compared on the basis of the $A_{I}$ index.

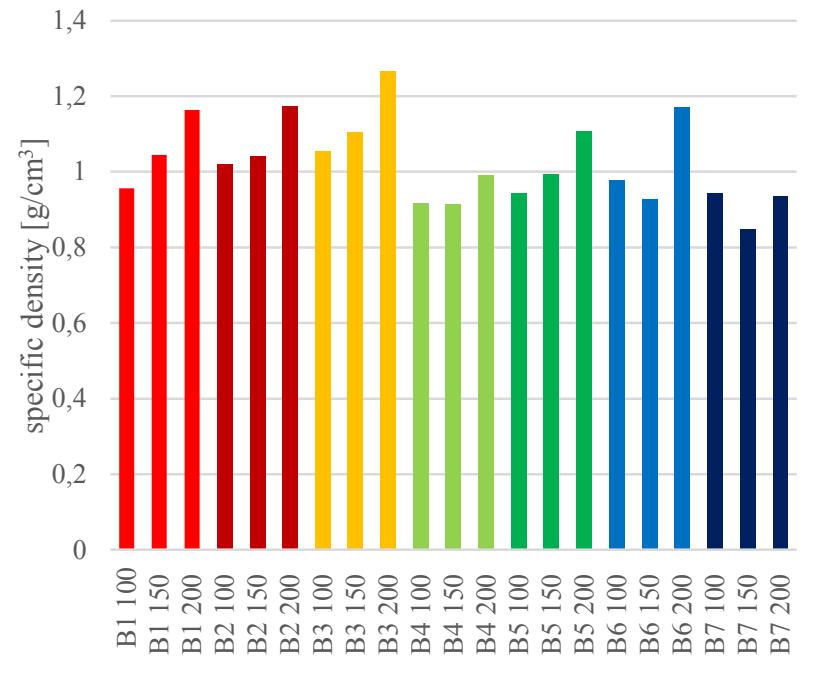

Fig. 2. Specific density of granulates.

On the basis of the absolute density measurement of the individual components of the mixtures, the common absolute density of each of the mixtures tested was calculated. The results of the absolute density determination of the individual components of the fertilizer mixes are presented in Table 2, while the calculated absolute density results of the tested mixtures in Table 3. 
Table 2. Absolute density of the fertilizer components

\begin{tabular}{|c|c|}
\hline Component & Absolute density $\left[\mathbf{g} / \mathbf{c m}^{\mathbf{3}}\right]$ \\
\hline Ash & 2,47 \\
\hline Postferment & 1,41 \\
\hline Urea & 1,35 \\
\hline Sulfur & 2,04 \\
\hline Phosphorite & 2,87 \\
\hline
\end{tabular}

The obtained results show that the components that form fertilizer mixtures are characterized by very different values of absolute density ranging from $1.35 \mathrm{~g} / \mathrm{cm}^{3}$ for urea to $2.87 \mathrm{~g} / \mathrm{cm}^{3}$ for phosphate. Depending on the proportion of the component in the mixture, its absolute density influences the absolute density of the mixture (Table 3). By analyzing the results of the absolute density of blends we can divide them into three groups. The first group consists of B1-B3 blends (absolute density above $2.1 \mathrm{~g} / \mathrm{cm}^{3}$ ), the second group is B4-B6 blends - about $1.9 \mathrm{~g} / \mathrm{cm}^{3}$ and B7 blend with the lowest absolute density of $1.7 \mathrm{~g} / \mathrm{cm}^{3}$.

Table 3. Absolute density of the fertilizer mixturers

\begin{tabular}{|c|c|c|c|c|c|c|}
\hline B1 & B2 & B3 & B4 & B5 & B6 & B7 \\
\hline 2,149 & 2,127 & 2,187 & 1,937 & 1,915 & 1,975 & 1,672 \\
\hline
\end{tabular}

Based on the results obtained, of the specific and absolute density the AI coefficient was detemined and the result is shown in the diagram in Figure 3:

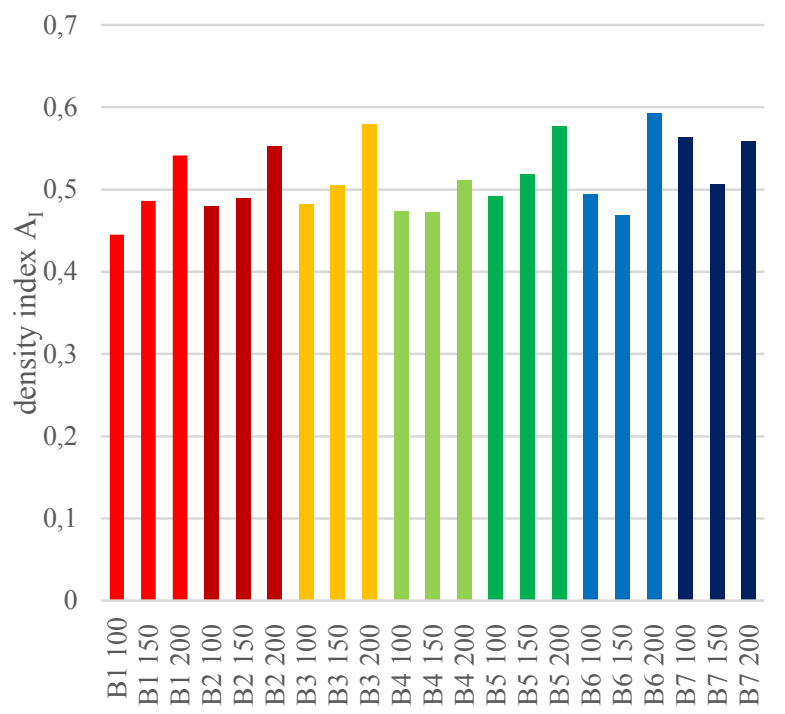

Fig. 3. Density index of granulates.

The level of the compaction factor has been set at an equilibrium level for the given pressure and is in the following ranges: $0.44-0.49 \mathrm{~g} / \mathrm{cm}^{3}$ (pressure $100 \mathrm{MPa}$ ), $0.47-0.51 \mathrm{~g} / \mathrm{cm}^{3}$ (pressure $150 \mathrm{MPa}$ ) $0.51-0.59 \mathrm{~g} / \mathrm{cm}^{3}$ (200MPa pressure). The obtained results indicate that, regardless of the contribution of components to the mixture at the given pressure, we obtain a similar degree of compaction. This means that the difference in the obtained results of the specific density of the obtained granules results from the different absolute density of the ingredients forming the blend.

Based on the measurements of absolute density of raw materials and specific density of granulates, porosity $p_{Z}$ of granulates was determined (Fig.4).

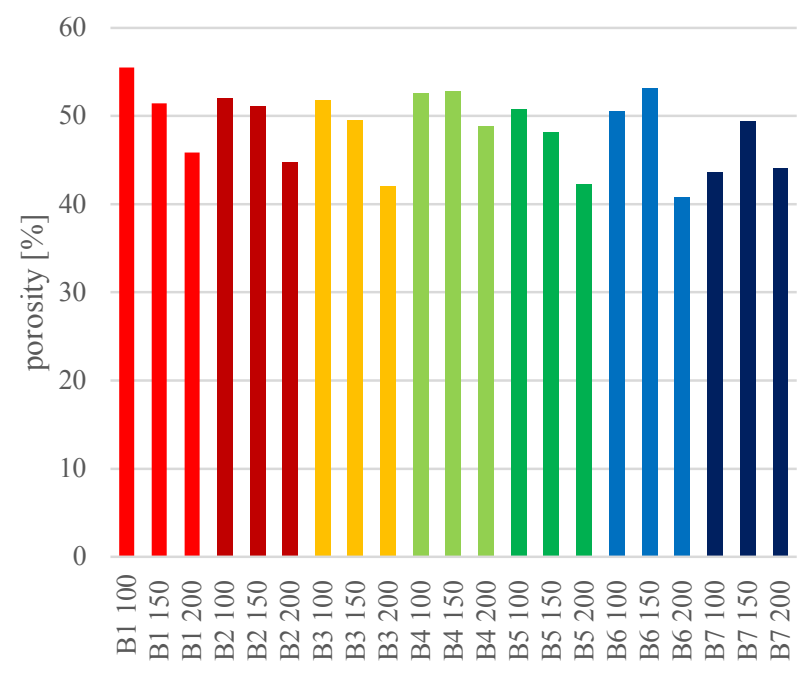

Fig. 4. Porosity of granulates.

The obtained values indicate that the granules made at a given pressure level have a porosity of $41-55 \%$. The presence of pores in the liver at this level is a processrelevant information. This means that it is possible to increase the granule's density by increasing the agglomeration pressure. From a utility point of view, this means that the granules thus produced have at least $40 \%$ of the space in which the nutrient-releasing water can penetrate during the decomposition of the granule in the soil.

\section{Conclusion}

Analysis of the obtained results, confirm that in the majority of cases, the increase of the agglomeration pressure results in an increase in the obtained specific density of the granules, which is a natural phenomenon, as free spaces (pores) are minimized during compression.

Analysis of the density index $A_{I}$ showed that, regardless of the contribution of components to the mixture at the given pressure, we obtain a similar degree of compaction. On the other hand the specific density of the 
obtained granules depends mainly on the absolute density of the ingredients forming the blend.

From the practical and technological point of view, the specific density of the granules should be at a comparable level (with the uniform geometry of the granules, the distance on which the granules are spread is determined by specific density) In such case, homogeneous density can be achieved by selecting a compaction pressure to obtain the density $1 \mathrm{~g} / \mathrm{cm}^{3}$. However. That's why further research on variation of agglomeration pressure should be carried out to obtain granules of comparable stability. It is also important to determine if the nutrient release from such granules is similar. The porosity of the granules causes that the granules can be easy penetrated by water what should stimulate fertilizer ingredients release from the granules.

Research was funded by the National Centre for Research and Development and the National Fund for Environment Protection as a part of GEKON program - project no. GEKON1/05/214543/38/2015 "Proecology production of organic and mineral fertilizers based on waste: by -porducts of combusiton and biogasification of biomass".

\section{References}

1. M. Bavutti, L. Guidetti, G. Allesina, A. Libbra, A. Muscio, S. Pedrazzi, Energy Procedia 45, 13441353 (2014). doi:10.1016/j.egypro.2014.01.141

2. G. Grinzi, L. Guidetti, G. Allesina, A. Libbra, P. Martini, A. Muscio, A. Proceedings of 20th European Biomass Conference and Exhibition (2012)

3. A. Kowalczyk-Juśko, M. Szymańska, Poferment nawozem dla rolnictwa Fundacja na rzecz Rozwoju Polskiego Rolnictwa, Warszawa, ISBN 978-83937363-6-2 (2015)

4. Niemiec M, Sikora J., Szeląg-Sikora A., Kuboń M., Olech E., Marczuk A. Przemysł chemiczny 96(3),685-688 (2017)

5. R. Vismara, R. Canziani, F. Malpei, S. Piccinini, Biogas da agrozootecnia e agroindustria Dario Flaccovio Editore, ISBN 978-88-579-0020-9 (2011)

6. C. Riva, V. Orzi, M. Carozzi, M. Acutis, G. Boccasile, S. Lonati, F. Adani, Sci. Total Environ. 547, 206-214 (2016)

7. Kuźnia M., Jerzaka W., Łykob P., Sikora J. Journal of Power Technologies. 95(2),158-165, (2015)

8. J. A. Alburquerque, C. Fuente, A. Ferrer-Costa, L. Carrasco, J. Cegarra, M. Abdad, M. P. Bernal, Biomass Bioenergy 40, 181-189 (2012)

9. Council Directive 91/676/EEC of 12 December 1991 concerning the protection of waters against pollution caused by nitrates from agricultural sources

10. H. Döhler, P. Schliebner, Verfahren und Wirtschaftlichkeit der Gärrestaufbereitung Darmstadt: KTBL (2006)
11. X. J. Huang, N. He, M.D. Liu, D. Yang, Y. J. Wang, Appl. Mech. Mater. 535, 523-527 (2014)

12. L. C. Ram, R. E. Masto, Earth Sci. Rev, 128, 52-74 (2014)

13. T. Kumar, K. Tedia, D. Devdas, J. Progressive Agric. 6, 1 78-82 (2015)

14. K. Mudryk, M. Wróbel, The acquisition and processing of biomass of Virginia mallow for energy purposes. ed. W. Piekarski, Wieś jutra, Warszawa, ISBN 978-83-62815-10-4 (2011)

15. M. Wróbel, J. Frączek, S. Francik, Z. Ślipek, K. Mudryk, Available at: http://tf.1lu.lv/conference/proceedings2013/Papers/1 21_Wrobel_M.pdf(2013)

16. G. Maj, A. Kuranc, Wybrane problemy z zakresu ekoenergii $i$ środowiska ed. W. Piekarski, Towarzystwo Wydawnictw Naukowych LIBROPOLIS, Lublin, ISBN 978-83-63761-46-2 (2014)

17. K. Mudryk, M. Wróbel, Autobusy 13, 10 166-169 (2012)

18. S. Mani, L. Tabil, S. Sokhansanj, Biomass Bioenergy 30, 648-654 (2006)

19. A. Karbowniczak, M. Wróbel, J. Rymar, Episteme 26 vol. 1 255-263 (2015)

20. M. Wróbel, J. Frączek, M. Jewiarz, K. Mudryk, K. Dziedzic, Agricultural Engineering 20, 4 207-217 (2017)

21. PN-EN ISO 18134-3:2015-11 